\title{
Digital storytelling as a tool for reflection in virtual reality projects
}

\author{
Deoksoon Kim¹ ${ }^{* 1}$ Merijke Coenraad ${ }^{2}$ and Ho Ryong Park ${ }^{3}$
}

* Corresponding author

E-mail: deoksoon.kim@bc.edu

1. Lynch School of Education \& Human Development, Boston College, MA, USA.

2. University of Maryland, College Park, MD, USA.

3. Racer Writing Center, Murray State University, Murray, KY, USA.

\section{Article Info}

Received: March 22, 2021

Revised: May 7, 2021

Accepted: May 17, 2021

10.46303/jcsr.2021.9

\section{How to cite}

Kim, D., Coenraad, M. \& Park, H. R. (2021). Digital storytelling as a tool for reflection in virtual reality projects. Journal of Curriculum Studies Research, 3(1), 101-121.

https://doi.org/10.46303/jcsr.2021.9

\section{Copyright license}

This is an Open Access article distributed under the terms of the Creative Commons Attribution 4.0 International license (CC BY 4.0).

\begin{abstract}
Reflection is essential for learning and development, especially among middle school students. In this paper, we describe how middle school students can engage in reflective learning by composing digital stories in a project-based learning environment employing virtual reality. Adopting multiple case study methods, we examine the digital stories of five students, together with classroom observations and interviews about their experiences, in order to explore how digital storytelling can allow students to reflect upon their experiences in a year-end capstone program. Creating digital stories allowed students to 1 ) reflect on their learning experiences teaching younger students with virtual reality, 2) present their reflections in multiple modalities, and 3 ) make connections between their present experiences and both past and future. This study shows how digital storytelling can enable multimodal reflection for middle school students, particularly in technology-focused project-based learning environments.

\section{KEYWORDS}

Digital storytelling; project-based learning; reflection; middle school learners. 


\section{INTRODUCTION}

Well-developed, meaningful curricular tasks enhance students' self-regulated learning and motivate them to become more engaged in learning (Park, 2019). Educators must design classes that facilitate more autonomous participation. To this end, project-based learning (PBL) $-a$ pedagogical method allowing students to take part in student-driven, experiential learning that centers around investigation and answering an authentic question-allows students to collaborate and develop critical thinking skills while focusing on their own ideas (Krajcik \& Blumenfeld, 2006). PBL often encourages students to think reflectively as they answer engaging questions and examine their own work and interactions with peers (Bell, 2010). Technological tools can facilitate this process (Mohamadi, 2018). The integration of new technologies and multimodal resources can support diverse tasks and projects, further enhancing reflection. One promising technology is digital storytelling.

Digital stories are 2-5-minute products which include images, texts, audio, voiceover, and other media. Ohler (2018) describes how digital stories use "personal digital technology to combine a number of media into a coherent narrative" (p. 15). Digital storytelling provides space and time for students to share their experiences and reflect upon those experiences, encouraging students to think more deeply about their learning (Kim \& Jia, 2020; Kim \& Li, 2020). In the process of making a digital story, students reflect on people, places, experiences, and objects in a new way as they include them in their work (Lambert, 2012). This process can be especially powerful for middle school students. Middle school learners need exposure to information as well as opportunities to connect the material to their thoughts about and experiences with the material, thus deepening their learning through reflection (Moon, 1999). In order to do this, they need opportunities to engage in metacognition and participate in guided reflection. With opportunities to reflect, students' mastery of content can be reinforced (Eisenbach, 2016).

Digital storytelling is an innovative way to tell and share stories that enables students to develop their voices and thus faciltates engagement in their learning (Park, 2019; Shelby-Caffey et al., 2014). Drawing on the instructional potential of technology-enhanced PBL, and recognizing the importance of reflection for students' learning, we designed a virtual realitybased teaching project for middle school students and adopted digital storytelling as a means for students to deepen and demonstrate their learning. Virtual reality (VR) is "the use of computer graphics systems in combination with various display and interface devices to provide the effect of immersion in the interactive 3D computer-generated environment" (Uğur \& Kalayci, 2007, p. 158) By combining virtual reality with digital storytelling, we were able to facilitate students' engagement and learning.

Digital storytelling has been studied in many contexts, but there is nonetheless limited research on how digital storytelling can enhance middle school students' reflective learning. We know of no research that studies the use of digital storytelling together with virtual reality in 
the classroom. In this study we show how combining virtual reality with the reflection made possible by digital stories can yield meaningful learning, facilitating participants' reflective learning. In this paper we answer the question: How did middle school students engage in the composition of digital stories and demonstrate reflective learning through these stories in a technology-enhanced project-based learning environment?

\section{LITERATURE REVIEW}

Existing research on project-based learning, digital storytelling, multimodal resources, and reflection provides the background for our study.

\section{Project-based learning}

In PBL, learning occurs through projects in which learners solve problems by developing and investigating questions and making decisions (Krajcik \& Blumenfeld, 2006; Thomas, 2000; Thomas et al., 1999). PBL projects centrally include inquiry, experience, and real-world-based problems. They provide students opportunities for cooperative learning, reflection, and authentic content learning and assessment (Diehl et al., 1999; Krajcik \& Blumenfeld, 2006; Moursund, 1999; Thomas, 2000). PBL experiences are student-driven and teacher-facilitated, giving agency and authority to the students (Bell, 2010). Overall, PBL encourages "students to learn by doing and applying ideas" (Krajcik \& Blumenfeld, 2006, p. 317). It encourages students to reflect on the work they are doing and the manner through which that work is completed (Bell, 2010). Research about the effectiveness of PBL suggests that it positively influences students' subject matter learning, as well as language learning, at various grade levels (Beier et al. 2019; Habok, 2015; Holmes \& Hwang, 2016; Kaldi et al., 2011; Vaca Torres \& Gómez Rodríguez, 2017).

\section{Digital Stories in K-12 Spaces}

Digital storytelling has been successfully implemented in both informal (Davis, 2005; DeGennaro, 2008; Freidus \& Hlubinka, 2002; Wexler et al., 2014) and formal (Sadik, 2008; Yang \& Wu, 2012) educational environments. Students taught using digital storytelling have outperformed students taught through information technology-integrated instruction, with regards to content knowledge, critical thinking, and learning motivation (Yang \& Wu, 2012). The more authentic experiences facilitated by digital storytelling may make students more motivated to explore and think critically. Yang and Wu (2012), for example, found an increase in critical thinking and motivation among students who completed digital storytelling compared to a control group. They show that "DST provided students with a meaningful authentic scenario related to their personal experiences, wherein a dynamic and interactive process of creating and publishing digital stories aroused the students' motivation in a rich multimedia classroom" (p. 11). 
Digital stories, in which creators tell a narrative using multimedia tools to combine audio, images, and video with voice-over narration, is a useful pedagogical strategy for extending narratives into the digital realm (Ohler, 2008). The composition of digital stories also encourages students to employ varied multimodal resources (Jewitt, 2008; Kim \& Li, 2020; Kress \& van Leeuwen, 2001) and to share their stories with others. Combining multimodal resources provides a new way to create meaning both in the individual components as well as in the whole (Hull \& Nelson, 2005).

Digital stories do often help students understand the subject matter, but the process that creators go through is even more important (Freidus \& Hlubinka, 2002). Digital storytelling can help authors to better understand the content and visualize their learning process (Jenkins \& Lonsdale, 2007). Digital storytelling also promotes collaboration between students (Yang \& Wu, 2012) and encourages reflection, which can itself be captured in the digital stories (Sandars, Murray, \& Pellow, 2008). As students work on their digital stories, they are prompted to focus on the storyline and make their stories both compelling and efficient (Freidus \& Hlubinka, 2002). This promotes reflection as students think about the people, places, and objects that are being combined in a new way (Lambert, 2012).

\section{Reflection}

Reflection helps us anticipate based on our understandings of what happened in the past (Schön, 1987). Because it facilitates engagement with diverse factors in a situation, reflective thinking is a critical element of learning (Atkins \& Murphy, 1993; Boyd \& Fales, 1983; Dewey, 1933), and it is particularly effective in experiential learning environments (Boyd \& Fales, 1983; Moon, 1999). Reflection helps students develop higher-order thinking by encouraging them to make connections between prior understanding and new knowledge and to think in both abstract and concrete terms (Hmelo \& Ferrari, 1997). It helps make students' individual experiences meaningful, which may help them understand the importance of learning in the real world (Brewer \& Jszefowicz, 2006).

However, students must be explicitly taught to reflect (Ryan, 2013). If students are directed toward reflection in learning environments, this reflective practice can facilitate learning and serve as a formative assessment tool to support both teaching and learning (Trauth-Nare \& Buck, 2011). Reflective learning environments, teaching methods, and scaffolding together have been shown to support learning (Song Koszalka, \& Grabowski, 2005). One method that can facilitate reflective practice is the construction of personal narrative.

This practice can serve as a cognitive tool for students' development, as the process of telling and writing down a story can be powerful (Davis, 2005). Technology can also be used to mediate reflective learning. It is particularly effective when combined with prompts and other guidance and with personal, human interactions such as those with peers or teachers (Kori et al., 2014). Technologies can create shared experiences and promote reflection through audio, 
video, and text when moderated by a teacher or other facilitator (Leinonen et al., 2016; Salmon, 2002).

All of this prior research has established that project-based learning is an important innovation, especially in science education, and that new technologies like virtual reality can engage students effectively. It has also established that digital storytelling can both engage students and foster reflection, which in turn facilitates subject matter learning. By studying a middle school classroom that combined project-based learning using virtual reality with digital storytelling, we show that a combination of these approaches can be particularly effective.

\section{METHODS}

Employing a qualitative multiple case study design (Lincoln \& Guba, 1985), we examine how digital stories facilitated reflection as part of a PBL experience in a "Teaching with Virtual Reality" capstone class at an urban Catholic middle school in the Northeastern US. In this study we explore middle school students' composition and sharing of multimodal digital stories about their experiences teaching with virtual reality. All of the names we use are pseudonyms.

\section{Setting and Participants}

The selection criteria were: (a) students' participation in a three-week capstone project, (b) their willingness to participate in the research study, and (c) their completion of the project. As their teacher, one of the authors worked with 6th and 7th grade (age 12-13) students during a threeweek capstone experience. Students were given a choice of seven capstone classes and selfselected into the capstone on Teaching with Virtual Reality. In total, there were ten students in the Capstone group and six students who consented to participate in the research study. Of these six students, one did not complete the project due to a family trip, so we analyze a total of five student cases. Gender was not used a criterion for selection, but the participants were all female (see Table 1).

Table 1: Participant background information

\begin{tabular}{|l|l|l|l|l|l|l|}
\hline Name & Ethnicity & Gender & Age & Grade & VR Topic & Teaching Partner \\
\hline Clara & Irish & Female & 12 & 6 th & Aurora Borealis & Gabby \\
\hline Rachel & Unknown & Female & 12 & 6 th & Stars & None \\
\hline Nancy & Canadian & Female & 13 & 7 th & Gettysburg & Vera \\
\hline Vera & Brazilian & Female & 13 & 7 th & Gettysburg & Nancy \\
\hline Gabby & Brazilian & Female & 12 & 6 th & Aurora Borealis & Clara \\
\hline
\end{tabular}

\section{Virtual Reality Capstone Project Procedure}

The capstone project was divided into two parts (see Figure 1). In Phase 1, students planned a lesson to teach younger, elementary grade students (ages 6 - 11) using virtual reality. The 
teacher provided scaffolded resources and students planned their lessons using visual aids as well as virtual reality to teach a topic of their choice. At the end of phase 1 , the students taught their lessons to elementary students in the same school. In Phase 2, the students used WeVideo to create a digital story describing their experiences planning and teaching their lesson. WeVideo is a web-hosted video editing application with a user-friendly interface that allows users to mix photos, video, audio, and music. The application includes a stock library of transitions and music clips that users can import. Students used photos and videos taken throughout their teaching experiences, as well as other images and multimodal elements. To assist students with the digital stories and reflection on their teaching experiences, the teacher provided students six questions following their presentations:

1. How did you integrate knowledge from various school subjects into a real-life situation?

2. What is the process that you used to reach your goal, why was this process successful, and how can the process be altered to better achieve your goal next time?

3. What are your strengths and weaknesses in carrying out a group project, and how can you use this information to help your group succeed?

4. What was the greatest challenge in planning a lesson and how did you overcome this challenge?

5. Why did you choose to teach what you did and the specific virtual reality trip(s) you led?

6. How did virtual reality engage the students that you taught?

At the conclusion of the capstone experience, students shared their digital stories with their peers.

Figure 1: Project Completion Timing

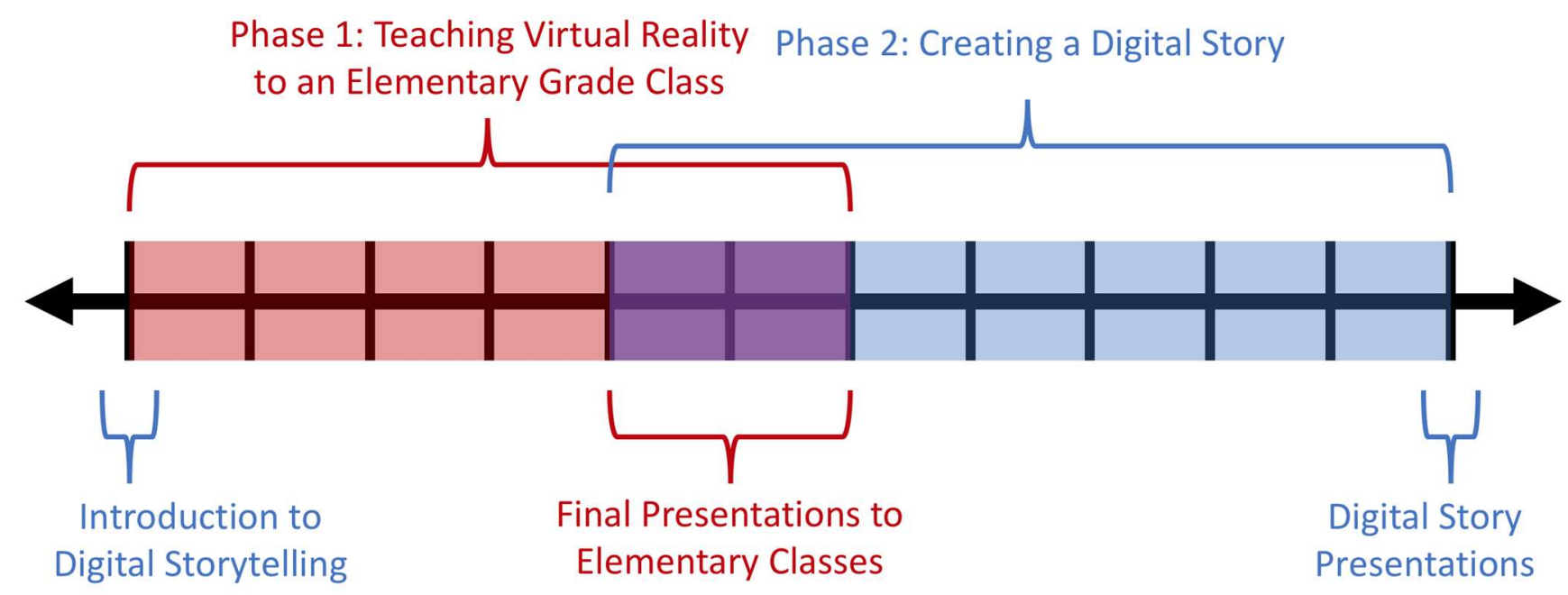




\section{Data Collection}

We examined three data sources: 1) reflective journals students kept about their experiences, 2) semi-structured interviews, and 3) the students' digital stories.

\section{Reflective journals}

While students were planning and presenting their lessons, they were encouraged to complete a daily journal with salient facts and ideas. Strict guidelines were not given to students about what they could include in their journal or how much they were to write, but the teacher did provide prompts (e.g., "I wonder...", "I was challenged by...", "I need to...", "I hope...") to guide their writing.

\section{Semi-structured interviews}

We conducted one or two semi-structured interviews for 30-45 minutes with each of the five focal students. These interviews occurred across the project, although most happened during phase 2. We asked students to describe their experiences teaching others' and using digital storytelling

\section{Student-created digital stories}

Each student produced a digital story based on their experiences. These stories were collected by the research and analyzed.

\section{Data Analysis}

Employing multiple case study methods, we analyzed the data inductively (Lincoln \& Guba, 1985), using content analysis on the participants' reflective journals and interviews. This systematic data analysis technique allowed us to categorize the substantial data (Hsieh \& Shannon, 2005; Renz et al., 2018). We triangulated across data sources, compared coding across researchers, and identified robust patterns (Kim \& Jia, 2020; Kim, et al., 2020). The data analysis involved three stages of coding. During open coding (Stage 1), we coded key words or concepts to capture what each participant said. In analyzing the data at stage 1, we drew in part on themes from previous studies (Truong-White and McLean, 2015), and we added emerging key concepts. At Stage 2, our coding sewed together saturated subcategories to form new thematic categories. We highlighted words or phrases of interest related to the participants' perceptions and experiences. We also wrote notes in the margins. For example, in one case we highlighted words such as reflection, multimodal resources, and experience, which the student used to describe aspects of her capstone activities and her DS. Then we went back through the transcripts and developed codes. We also looked through our notes and highlighted text. For example, we developed the code interest level. At Stage 3, we reviewed the transcripts again and created themes - for example, reflections, identities. After each case study, we compared and contrasted findings across cases. Through a cross case analysis, we finalized the themes. We also analyzed other qualitative data, including observation reports, researchers' journals, and artifacts, using the same coding procedure. We analyzed the digital stories using a 
multimodal analytical framework that Kim \& Jia (2020) developed based on the Systemic Functional Linguistics.

This framework analyzes representational, interpersonal, compositional, and sociocultural dimensions. The first, representational, focuses on the objects, places, and participants in the video. What are the elements that we can see and hear? Who are the participants? What objects are involved? How are they visually and verbally represented? The second, interpersonal, focuses on the relationships between viewers and the author, as well as relationships between subjects within the video (for example, a teacher and a student). This explores relationships across the screen and relationships within the screen. The third, compositional, focuses on the structure of the digital story. How is the information presented? How are the parts combined to create a coherent whole that expresses the author's voice? The last dimension, sociocultural, focuses on the author's own socio-cultural and political position, as well as the social context represented in the composition.

\section{FINDINGS}

The analysis revealed several ways in which students reflected on, learned subject matter, and articulated their voices through digital stories, as well as how the use of multimodal resources enhanced this. We begin by presenting a short description of each participating student and her digital story. Then we provide a cross-case analysis of the reflection, learning, and articulation of voice facilitated by the multimodal resources in digital stories.

\section{Cases}

The Teaching with Virtual Reality capstone was designed to allow individual students to choose areas of interest. Each case illustrates how a different topic facilitated student reflection and learning.

\section{Clara}

Clara was a $6^{\text {th }}$ grader who was quiet and kept to her small group of friends. Clara was initially hesitant to participate in class during full-group conversations, but she nonetheless worked hard. Clara planned and taught a lesson on the Aurora Borealis for fifth-grade (10-11-year-old) students together with her friend Gabby. They identified the topic after learning about and becoming interested in the Aurora Borealis in science class. Clara's digital story presents the process of preparing for and teaching the lesson, along with reflections about overcoming her shyness and having to present a lesson in front of a large group of students. She narrated the story from a first-person "our" perspective, referencing her collaboration with Gabby. She used audio tracks that changed with each scene and marked transitions between images. Clara worked hard to create a digital story that she was proud to share, and she used the affordances of the platform to speak confidently.

\section{Gabby}

Gabriella was a $6^{\text {th }}$ grader who partnered her friend Clara to teach about the Aurora Borealis. She focused on making the class interesting to the students by presenting an engaging topic and 
using student-centered teaching methods. Gabby's digital story also tells an "our" story, centering both her and Clara and describing their planning and teaching, with subsequent reflections on the experience. She focused on describing the images as they are shown on the screen. Throughout the digital story, Gabby had a confident expository voice and used multiple audio tracks. Gabby successfully employed transitions to blend the pictures and videos within her digital story.

\section{Vera}

Vera, a $7^{\text {th }}$ grade student, chose to teach about Gettysburg and Abraham Lincoln because it would be "easy to explain to an elementary class." She worked with her classmate Nancy to present this lesson to fourth-grade (9-10-year-old) students. In her digital story, Nancy focused on preparing to teach, while offering spontaneous reflections about the experience. Her reflections focused on collaboration and on her feelings of nervousness but increasing comfort with teaching. Vera also included reflection about the process of creating a digital story, which she found stressful but, in the end, fun. Vera's digital story was told as a "me" story. While she acknowledged working with another student, she mostly focused on her personal feelings. Vera used audio throughout her story and allowed the audio associated with the videos to play at the same time as the music. She presented a mixture of images and videos with transitions between them to create a reflective story.

\section{Nancy}

Nancy, a $7^{\text {th }}$ grade student, partnered with her friend Vera, presenting to fourth grade students about Abraham Lincoln and Gettysburg. Nancy advocated for the topic after a class trip to Philadelphia and Gettysburg. Nancy's digital story was told as an "our" story, at times using two voices (her and Vera) rather than just one. Nancy described her overall experience and focused on the enactment of the virtual reality lesson on Gettysburg. Her story used a cheerful and confident voiceover. She successfully used multimedia images, videos, transitions, and audio.

\section{Rachel}

Rachel, a sixth-grade student, elected to work alone during the Teaching with Virtual Reality capstone. She taught about the stars, due to her own fascination with the subject. Rachel asked to teach a third grade (8-9-year-old) class, because her brother was in the class and she felt that she understood what was appropriate for third-grade students. Rachel's digital story chronologically described the process of planning, preparation, and presentation. Within the digital story, Rachel focused on her frequent habit of making things more complicated than was necessary and the need to simplify. She described a balance of excitement and nervousness, especially about the length of her story. Her voice in the digital story communicated both excitement and reflection. Rachel utilized images, including emojis and cartoons, as well as music to express her feelings throughout the story. 


\section{Teaching with Virtual Reality (VR)}

The students' reports about the process of teaching were particularly interesting. In the interviews, students described how they were nervous about what was for them the new activity of teaching. They drew on their own experiences as students, and they worked diligently to plan their lessons using technology and VR. In order to make their lessons diverse and dynamic, students searched for resources on the internet and emphasized multimodal resources, such as images, videos, and audio. The participants believed finding and utilizing interesting multimodal resources would facilitate students' engagement and learning. For example, Rachel said she felt successful when she figured out how to sequence her lesson, found a kid-friendly and informative video, and shortened another key video.

Vera also describes how she worked to find good pictures and other texts which would interest the students. The participants believed that using technology was an effective way to meet their teaching goals. With respect to technology use, Rachel said, "The virtual reality was very helpful because it kept the students really engaged by showing them pictures that look like the students are seeing auroras from their own point of view." They found the Virtual Reality tool particularly useful in their teaching of elementary students.

Several students took the opportunity in their digital stories to reflect on their future careers. These reflections included thinking about teaching as a career and the role that having the chance to teach a class played in their ideas about what they might do as adults. For Clara, creating the digital story "helps like to start thinking like what do I want to do because if I do become a teacher, I don't want to be like just like sit out on your desk and like umm... copy this... like I want to be like, more interesting."

Rachel reflected on both her past and her future while working on her digital story. She recalled, "I've done teaching...ever since I was like a two-year-old, I always wanted to be like a teacher, and like...I've taught, teach, my brother stuff, he knows the ABCs before he even got into school." As Rachel continued to share her journey and reflect on the decision of whether to pursue teaching, she added that,

I've been drifting farther and farther away from teaching for a while now, and I feel like now I'm more close to the idea of being a teacher of some sort. Yeah cause I actually went through this phase where I was trying to be in the mission control in NASA [National Aeronautics and Space Administration] so... I wanted to be at mission control at NASA so...now I'm drifting more towards teaching because I haven't taught like for a while, and I'm back into it...it's like YES! I'm back! (Rachel Interview)

Participating in the capstone experience and creating her digital story allowed Rachel to process her experiences teaching and reconsider potential career trajectories.

\section{Reflection through the Composition of Digital Stories}

Creating the digital stories gave the students an opportunity to reflect on their experiences teaching younger students using VR. They had opportunities to reflect as they selected 
components for their story and as they worked to knit it together into a coherent whole. As Gabby explained in her interview, "the WeVideo [digital story] really, like, brings everything together and helped with my experience." The creation of a digital story helped her to think through everything that she had accomplished and bring it together in a way that was meaningful, thus facilitating reflective learning. Rachel echoed this: "I started thinking about, like, my whole process and I started getting really deeper into it and usually end up changing my opinion or learning something about it so... I am excited to...finish the WeVideo."

In the capstone program, the teacher emphasized reflection by providing questions. Students were not required to use the questions supplied by the teacher, but many did choose to use them in their stories. Some students did this by using the questions as section dividers in their stories. In these cases, the students tended to present the question as a visual title. In other cases, students used some or all of the questions to produce content, but they did not focus sequentially on each question. Digital storytelling also prompted the students to think through their individual successes and challenges and to discuss how practical, project-based experiences such as teaching with virtual reality might shape their life experiences.

Composing digital stories also offered students space and time to reflect on what they had learned. Within their digital stories, students mainly reflected on their experiences teaching VR-based lessons to elementary students. Overall, they used their digital stories to reflect by sharing their experiences and accomplishments chronologically, beginning in the planning stages of lesson creation, depicting the lessons they gave to elementary school students, and ending with discussions about creating their digital stories themselves. In sharing their experiences, students described not only what they did, but also the feelings they had. For example, when discussing the process of creating and planning the teaching in her digital story, Rachel said:

When Thursday came, I got really worried, so I took a deep breath and figured out my goals for the day. I needed to shorten my video, finish my flashcards, fix my game, and go through my lesson to work out any kinks. And luckily, I finished my lesson just in time and I felt good about my practice presentation on Monday. But the question still remained, would my lesson still be too long? Would my material be too confusing and bore people? I started getting more nervous. (Rachel, Digital Story)

By examining moments of success as well as challenges faced throughout the projects, students created opportunities to reflect on their experiences. For example, in her digital story Clara discussed working with Gabby as being crucial because of their strong partnership and ability to work well together. But they also faced a challenge, with both being nervous about presenting and disagreeing about who would speak. Clara celebrated finishing her teaching later in the digital story, noting that "after [Gabby] and I finished teaching both classes we felt very 
relieved." This kind of reflection helped them process how they felt about specific lessons, and how they felt about possible future careers.

\section{Sharing Experiences Through Multimodal Resources}

While most reflection was about their experiences, the successes and challenges faced, the students also reflected on the process of creating a digital story and incorporating multimodal components. For Vera, the experience of creating a digital story involved mixed emotions. In her story she explained:

WeVideo has been a fun and a very stressful experience for me personally. It has been stressful because it is hard to find a way to make the video flow, and it has been fun for me as well because we can add videos and music and we can add different text (Vera, Digital Story)

For others, creating a digital story was an opportunity to express themselves through planning and the final product. Multiple modalities were an important theme. Nancy described the process this way: "you have more freedom with this because you can pick what you want to do. Like you can pick the font you want, you can pick the type of, like, texts you want, and the music and I find that really cool." In her digital story, Nancy reflected on her deliberate use of audio, mixture of still images and video, titles, and transitions. Clara echoed Nancy's feelings about digital stories. She said that creating a digital story is:

fun because when you write an essay, you can't make it, like you can't really add music in google slides, but you can add music in WeVideo, and like, you could tell yourself and like you could read it to make it, to like people don't have to like oh what does this say, or when you could just like hear someone read it to you (Clara; Interview).

Even though creating a digital story was difficult at times, it allowed students to express themselves in a novel way and utilize multimedia technologies to do so. In the following section, we describe how students reflected about four different modalities: voiceover narration, image use, audio mixing, and on-screen text.

\section{Voiceover}

All five students employed voice-over audio narration of them telling the story while images or text appeared on screen, as the main means of communication. Although not every segment included voice-over audio, most information communicated in the stories came through such narration. Most stories were told from a first-person point of view, emphasizing what happened to their students across the capstone project. While not all students were as direct, Vera began her story, "Hi, my name is Vera and I'm going to talk to you about my experience with teaching with virtual reality." In this introduction, we see Vera place herself as the expert within the presentation and pointing directly to the topic, her experiences in the capstone. Typically, students described their emotions in the voice over narration. For example, when she described her planning for teaching, Rachel said, "I got really worried that my lesson would be too 
confusing for elementary students. What if I got a first-grade class to teach? How would I explain what hydrogen and helium is to them?" In this sequence, Rachel reflected both on her thought process when lesson planning and on the emotional response she had when realizing the difficulty of the content she aimed to teach.

\section{Image Use}

Students used a variety of images in their digital stories, such as photographs, emojis, student created images, and GIFs (a file format for the compression and storage of visual digital information), as well as videos. While most of the images in students' digital stories were of them either working or teaching (Figure 2a), students also employed downloaded images such as emojis or characters (Figure $2 \mathrm{~b}$ ) and student-created images (Figure $2 \mathrm{c}$ ). The combination of these image types allowed students to illustrate what they were describing in their voice over. Gabby elected to use a GIF rather than a static image on her title page (Figure $2 \mathrm{~d}$ ). This added movement, an affordance that was enhanced by the use of video editing software to create the digital stories.

Figure 2: Images from student digital stories; (a) Use of photographs in Vera's digital story, (b) Use of emojis in Rachel's digital story, (c) Use of student-created images in Rachel's story, (d) Use of a GIF on the title slide in Gabby's digital story.

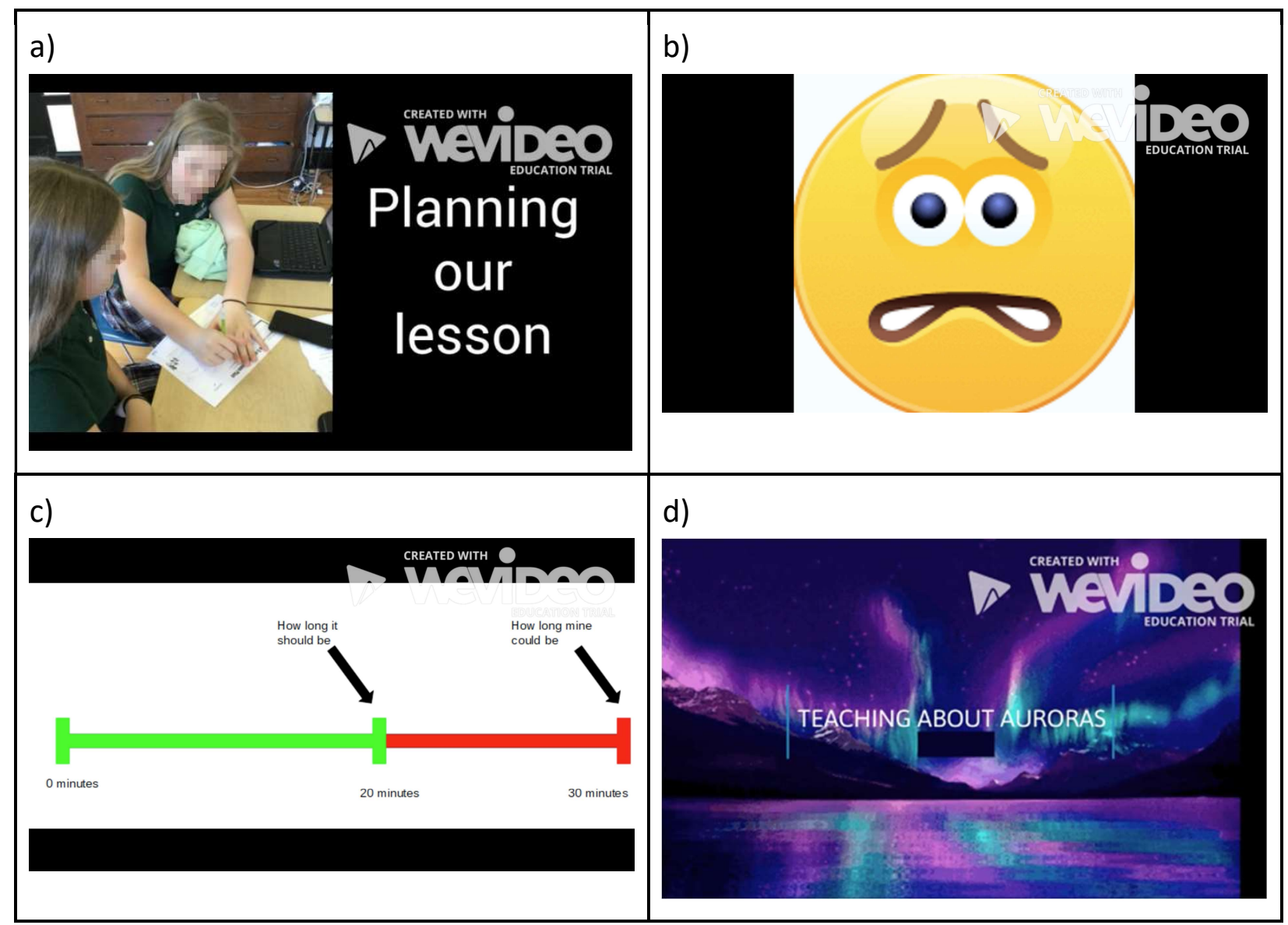


Image use within student's digital stories was both emotive and topical, as is seen in two examples from Rachel's digital story (Figure 3 a \& b). This demonstrates not only the students' experiences, but also the topics they taught and the connection between their experiences using VR to teach and the creation of digital stories. When creating topical images, students also remixed images of their teaching into their digital stories by utilizing screen capture images of their class slide presentations.

Figure 3: Varied image use in student digital stories; (a) Topical image from Rachel's digital story about teaching on the stars, (b) Emotive image used in Rachel's digital story, (c) Screenshot of slides used in Vera's digital story.

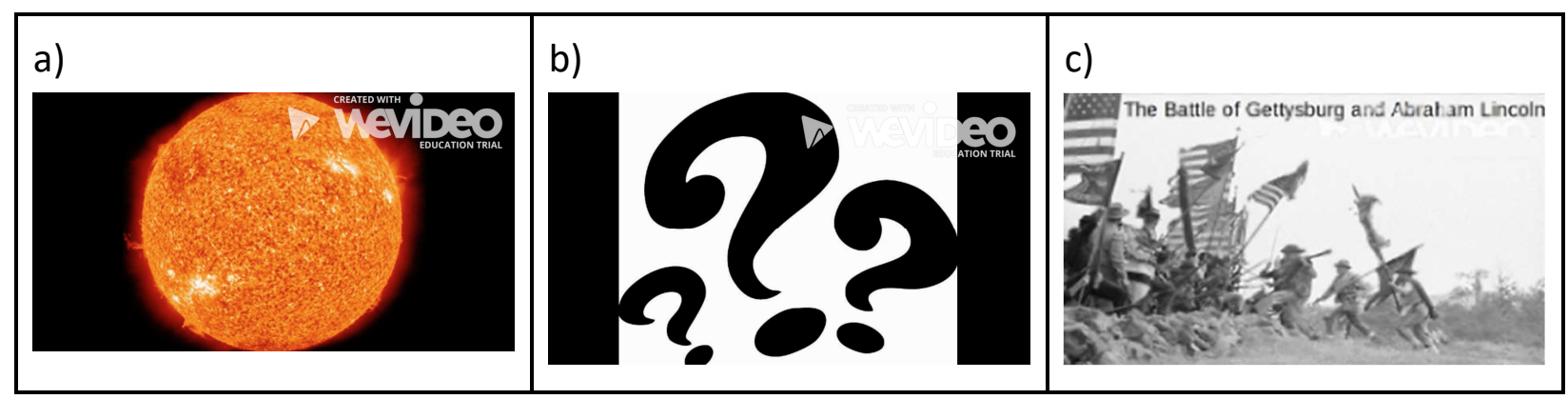

Students also used images of the video-creation software itself in their digital stories. Students frequently discussed creating their digital stories, and some included screenshots of the process of composing the story using WeVideo. Figure 4 captures a screen shot of digital story creation, with Clara communicating to the audience about her process of composition by inviting them into her creator's room in WeVideo.

Figure 4: Screenshot of creating digital story in WeVideo from Clara's Digital Story

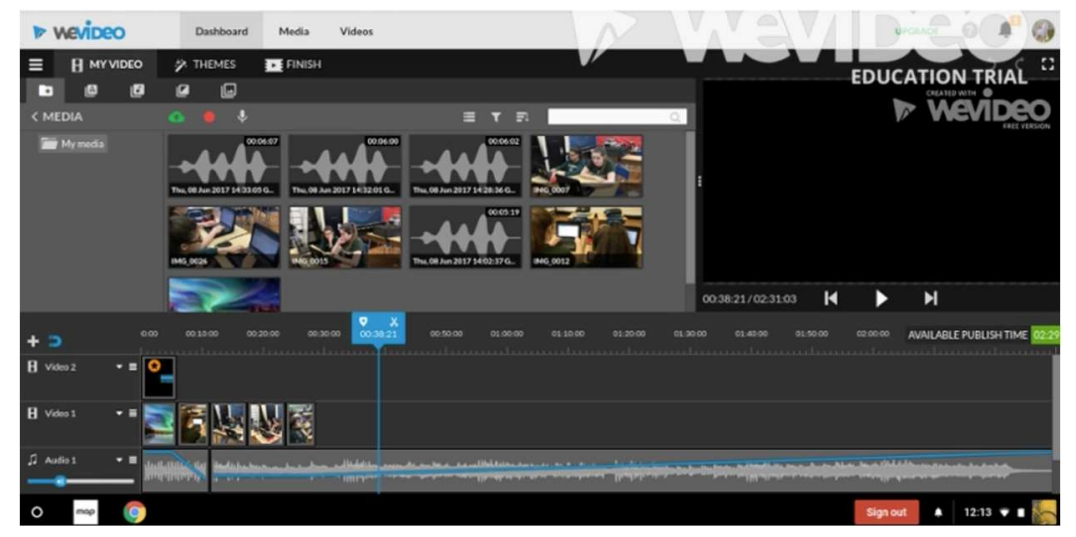

\section{Audio Mixing}

Audio was an important part of students' digital stories. All of the students used background music and other audio within their digital stories. Typically, students used 1 or 2 different audio tracks. This was another opportunity to express themselves. In her interview, Nancy characterized the digital story creation process by saying, "I put in a lot of background music in it so, like, maybe they could tell that oh I like music, and I do like music." 
Background soundtracks were also an opportunity for students to evoke emotion in the viewer. In her story, Clara used music as a tool to show how she was feeling during certain stages of the process. When she discussed working with her partner to plan the lesson, Clara used upbeat music, but when she described the class presentations, a part of the process she described as challenging because she is shy, the music was more melancholy and tentative.

Uniquely, Gabby remixed the standard music tracks provided within the video editing software by layering music within her digital story. In doing so, she created new varieties of music as well as areas of dissonance between tracks. Gabby used a main soundtrack throughout her entire story. The title slide begins her digital story with a second track overlaying the main one. Then, she removed the second track and layered the sound of a shaker, creating her own variation of the original track. This main track plus shaker combination continued as Gabby provided an introduction to the lesson and discussed what went well. It ended as she began to reflect on the weakness of her team. In addition, a third track was overlaid on a portion of her digital story, overlapping with the shaker sound to have three sounds at once, then continuing after the shaker ends.

\section{On-Screen Text}

The students used on-screen text to create segments in their digital stories. Many students used on-screen text to introduce segments, either questions (Figure 5a) or statements (Figure 5b). Uniquely, in Nancy's story, reflection came not just through the voice over, but also in the texts she used throughout the story. For Nancy, titles were not only transitional objects, but also a means of imparting information to the viewer (Figure $5 c$ ).

Figure 5: Use of text and titles in Digital Stories; (a) Question text to create segments in Clara's Digital Story, (b) Statement text to create segments in Gabby's Digital Story, (c) Text on screen to impart information in Nancy's Digital Story.

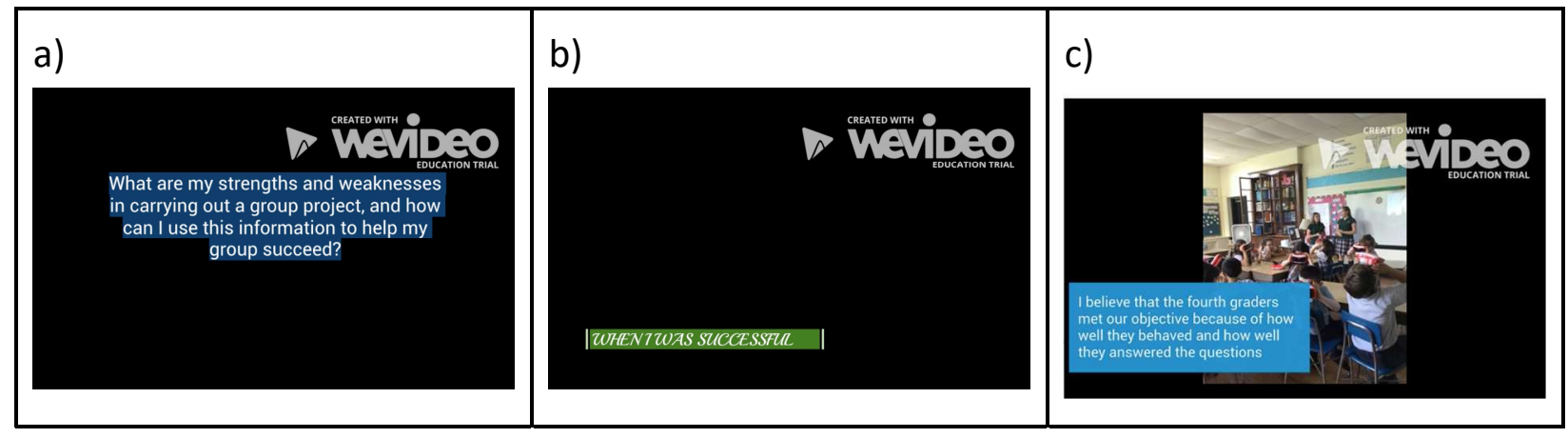

\section{DISCUSSION}

By developing a capstone experience that brought together teaching with virtual reality and reflection through the composition of digital stories, this project-based learning experience gave students opportunities to experience technology in the classroom, introduce other students to 
that technology, and utilize multimodal digital story production to share and reflect on the experience of teaching elementary school students using VR. Others have described how selfauthorship in the process of writing personal narratives can promote reflective learning (David, 2005; Kim, et. al, 2020), and we found a similar process in the creation of these digital stories.

The projects helped students to think through their learning process (Kori et al., 2014). The development of digital stories allowed students to script a narrative about their process and to think through their reactions to the experience. The digital stories within virtual reality project-based learning both helped students learn and helped them to understand their learning process (Jenkins \& Lonsdale, 2007). Students had the opportunity to learn about the teaching processes and pedagogical strategies for teaching with technology like virtual reality. This was a unique experience that most middle school students do not have. Their stories communicated their reflections about teaching elementary students, composting the digital stories, and their own personal growth.

\section{Telling the stories: Students' expression and reflection}

Students expressed themselves and their reflections through their digital stories. This facilitated learning because the reflections provided an opportunity to look back on both content and process. They were able to use digital storytelling as a means of reflection that can promote both identity building and learning (David, 2006; DeGennaro, 2008; Gee, 1999). Expressing their voices, students assembled various multimodal objects such as images, audio, texts, and narration, often remixing various components. The digital storytelling enabled the students to express themselves in distinctive ways (Author, et.al, 2020; Authors, 2021). For example, Clara and Nancy shared feelings about their stories. Vera and Rachel describe their anxieties about teaching the younger students. They also incorporated images and video clips to create particular effects. Gabby, for example, used GIFs on her title page to special effect. They combined multi modal resources and expressed their feelings in a way that would captivate their audience and communicate their own development across their teaching experience.

\section{Pedagogical Implications}

Given that this project occurred in two parts, first teaching with virtual reality and then creating a digital story, it was important to provide students with time to reflect before the segment where they had time to work on their digital stories. The reflection took place by having students respond to a sentence prompt each day in their journal. How much students wrote varied, but by writing students were able to record their process and refer to their notes about how they felt. Many students drew directly from their journals when creating their digital stories. Additionally, students and facilitators took pictures throughout the process. This allowed students to remember their process through images and ensured that images were available for their digital stories. 
Through this connection between technology enhanced project-based learning, together with digital storytelling, students had the opportunity to regulate their own learning and knowledge and to develop agency by reviewing their experiences. When given prompts, students tended to answer exactly these question in their reflection, and most students did not reflect beyond the questions in their work. While these questions were helpful in directing student reflection, then, it is important for teachers to craft the questions carefully given their direct use by students. Teachers could also consider a mini-lesson to teach students how to translate the questions into a broader reflection and how to add their own thoughts beyond the prompts.

Composition of digital stories also gave students an opportunity not only to engage in a formative experience, but also to reflect on that experience and what it meant to them. As middle school students develop their identities and explore, such reflection is a key opportunity for growth. Students used their digital stories not only to present their experiences through a combination of multimodal resources, but also to describe how these experiences related to their own past and future and to their sense of self. Together, technology-focused project-based learning and digital storytelling opened opportunities for new experiences and reflection on how those experiences affected students.

\section{Ethics}

This research was approved by an Institutional Review Board at the project's home institution. Research approval included active parental consent and child assent with all youth involved. Data are presented using pseudonyms to preserve the anonymity of research participants.

\section{REFERENCES}

Atkins, S., \& Murphy, K. (1993). Reflection: A review of literature. Journal of Advanced Nursing, 18, 1188-1192. https://doi.org/10.1046/i.1365-2648.1993.18081188.x

Beier, M. E., Kim, M. H., Saterbak, A., Leautaud, V., Bishnoi, S., \& Gilberto, J. M. (2019). The effect of authentic project-based learning on attitudes and career aspirations in STEM. Journal of Research in Science Teaching, 56(1), 3-23.

https://doi.org/10.1002/tea.21465

Bell, S. (2010). Project-based learning for the 21st century: Skills for the future. The Clearing House, 83, 39-43. https://doi.org/10.1080/00098650903505415

Boyd, E., \& Fales, A. (1983). Reflective learning: Key to learning from experience. Journal of Humanistic Psychology, 23(2), 99-117. https://doi.org/10.1177/0022167883232011

Brewer, S. M., \& Jozefowicz, J. J. (2006). Making economic principles personal: Student journals and reflection papers. The Journal of Economic Education, 37(2), 202-216. https://doi.org/10.3200/JECE.37.2.202-216

Davis A. (2005). Co-authoring identity: digital storytelling in an urban middle school. THEN: Technology, Humanities, Education, \& Narrative. Retrieved from http://thenjournal.org/feature/61. 
DeGennaro, D. (2008). The dialectics informing identity in an urban youth digital storytelling workshop. E-Learning, 5(4), 429-444.

Dewey, J. (1933). How we think: A restatement of the relation of reflective thinking to the educative process. Heath.

Diehl, W., Grobe, T., Lopez, H., \& Cabral, C. (1999). Project-based learning: A strategy for teaching and learning. Center for Youth Development and Education, Corporation for Business, Work, and Learning.

Eisenbach, B. B. (2016). Considering the Virtual Classroom: A Call to Middle Level Education Programs. Middle Grades Review, 2(1), 1-7.

https://scholarworks.uvm.edu/mgreview/vol2/iss1/3

Freidus, N., \& Hlubinka, M. (2002). Digital storytelling for reflective practice in communities of learners. SIGGROUP Bulletin, 23(2), 24-26. https://doi.org/10.1145/962185.962195

Gee, J. P. (2000). Identity as an analytic lens for research in education. Review of Research in Education, 25, 99-125.

Habok, A. (2015). Implementation of a project-based concept mapping developmental programme to facilitate children's experiential reasoning and comprehension of relations. European Early Childhood Education Research Journal, 23(1), 129-142. http://dx.doi.org/10.1080/1350293X.2014.991100

Habók, A., \& Nagy, J. (2016). In-service teachers' perceptions of project-based learning. Springer Plus, 5(83). http://doi.org/10.1186/s40064-016-1725-4

Hmelo, C. E., \& Ferrai, M. (1997). The problem-based learning tutorial: Cultivating higher order thinking skills. Journal for the Education of the Gifted, 20(4), 401422. https://doi.org/10.1177/016235329702000405

Holmes, V., \& Hwang, Y. (2016). Exploring the Effects of Project-Based Learning in Secondary Mathematics Education. Journal of Educational Research, 109(5), 449-463. https://doi.org/10.1080/00220671.2014.979911

Hsieh, H.-F., \& Shannon, S. E. (2005). Three approaches to qualitative content analysis. Qualitative Health Research, 15(9), 1277-1288. doi.org/10.1177/1049732305276687

Hull, G. A., \& Nelson, M. E. (2005). Locating the semiotic power of multimodality. Written Communication, 22(2), 224-261.

Jenkins, M., \& Lonsdale, J. (2007). Evaluating the effectiveness of digital storytelling for student reflection. https://www.semanticscholar.org/paper/Evaluating-theeffectiveness-of-digital-for-student-JenkinsLonsdale/dcc1f80c269f04029f45594c6caaab73e4de24b4

Jewitt, C. (2008). Multimodality and Literacy in School Classrooms. Review of Research in Education, 32, 241-267. https://doi.org/10.3102/0091732X07310586

Kaldi, S., Filippatou, D., \& Govaris, C. (2011). Project-based learning in primary schools: Effects on pupils' learning and attitudes. Education 3-13, 39(1), 35-47. https://doi.org/10.1080/03004270903179538 
Kim, D. \& Jia, F. (2020). "Ever wondered what Schizophrenia was?" Three bilingual students' digital storytelling about mental disorders. Journal of Curriculum Studies Research. 2(2), 144-169. https://curriculumstudies.org/index.php/CS/article/view/67/31

Kim, D. \& Li, M. (2020). Digital storytelling: Multimodality, project reflection, and identity. Journal of Computers in Education. https://doi.org/10.1007/s40692-020-00170-9

Kim, D., Long, Y., Zhao, Y., Zhou, S., \& Alexander, J. (2020). Teacher professional identity development through digital stories. Computers and Education.

https://doi.org/10.1016/j.compedu.2020.104040

Kori, K., Pedaste, M., Leijen, A., \& Mäeots, M. (2014). Supporting reflection in technology enhanced learning. Educational Research Review, 11, 45-55.

DOI: $10.1016 /$ i.edurev.2013.11.003

Krajcik, J. S., \& Blumenfeld, P. C. (2006). Project Based Learning. In R. K. Sawyer (Ed.), The Cambridge handbook of the learning sciences (pp. 317-333). Cambridge University Press.

Kress, G., \& van Leeuwen, T. (2001). Multimodal discourse: The modes and media of contemporary communication. Arnold.

Kroger, J. (2017). Identity Development in Adolescence and Adulthood, 1(December), 1-26. https://doi.org/10.1093/acrefore/9780190236557.013.54

Lambert, J. (2012). Digital Storytelling: Capturing Lives Creating Community (4th ed.). Routledge.

Leinonen, T., Keune, A., Veermans, M., \& Toikkanen, T. (2016). Mobile apps for reflection in learning: A design research in K-12 education. British Journal of Educational Technology, 47(1), 184-202. https://doi.org/10.1111/bjet.12224

Leondari, A., Syngollitou, E., \& Kiosseoglou, G. (1998). Academic achievement, motivation and future selves. International Journal of Adolescence and Youth, 7, 165-177.

Lincoln, Y. S., \& Guba, E. G. (1985). Establishing trustworthiness. Naturalistic Inquiry, 289(331), 289-327.

Mohamadi, Z. (2018). Comparative effect of project-based learning and electronic projectbased learning on the development and sustained development of English idiom knowledge. Journal of Computing in Higher Education, 30(2), 363-385.

https://doi.org/10.1007/s12528-018-9169-1

Moon, J. A. (1999). Reflective in learning and professional development: Theory and practice. Routledge. https://doi.org/10.4324/9780203822296

Moursund, D. (1999). Project-based learning using information technology. International Society for Technology in Education.

Ohler, J. (2008). Digital storytelling in the classroom: New media pathways to literacy, learning, and creativity (1st ed.). Corwin Press. 
Park, H.-R. (2019). ESOL preservice teachers' experiences and learning in completing a reflection paper and digital storytelling. Australasian Journal of Educational Technology, 35(4), 63-77. https://doi.org/10.14742/ajet.4117

Renz, S. M., Carrington, J. M., \& Badger, T. A. (2018). Two strategies for qualitative content analysis: An intramethod approach to triangulation. Qualitative Health Research, 28(5), 824-831. doi.org/10.1177/1049732317753586

Ryan, M. (2013). The pedagogical balancing act: Teaching reflection in higher education. Teaching in Higher Education, 18(2), 144-155. http://dx.doi.org/10.1080/13562517.2012.694104

Sadik, A. (2008). Digital storytelling: A meaningful technology-integrated approach for engaged student learning. Educational Technology Research and Development, 56(4), 487-506. https://doi.org/10.1007/s11423-008-9091-8

Sandars, J., Murray, C., \& Pellow, A. (2008). Twelve tips for using digital storytelling to promote reflective learning by medical students. Medical Teacher, 30(8), 774-777.

Schön, D. A. (1987). Educating the reflective practitioner. Jossey-Bass Publishers.

Shelby-Caffey, C., Úbéda, E., \& Jenkins, B. (2014). Digital storytelling revisited: An educator's use of an innovative literacy practice. The Reading Teacher, 68(3), 191-199. https://doi.org/10.1002/trtr.1273

Song, H-. D., Koszalka, T. A., \& Grabowski, B. L. (2005). Exploring Instructional Design Factors Prompting Reflective Thinking in Young Adolescents. Canadian Journal of Learning and Technology, 31(2). Retrieved from

https://www.cjlt.ca/index.php/cjlt/article/view/26498/19680

Thomas, J. W. (2000). A review of research on project-based learning. San Rafael, CA: The Autodesk Foundation. Retrieved from http://www.bobpearlman.org/BestPractices/PBL Research.pdf

Thomas, J. W., Mergendoller, J. R., and Michaelson, A. (1999). Project-based learning: A handbook for middle and high school teachers. The Buck Institute for Education.

Trauth-Nare, A., \& Buck, G. (2011). Using reflective practice to incorporate formative assessment in a middle school science classroom: A participatory action research study. Educational Action Research,19(3), 379-398.

https://doi.org/10.1080/09650792.2011.600639

Uğur A., Kalayci T.E. (2007) Automatic Generation of Virtual Computer Rooms on the Internet Using X3D. In Y. Shi, G.D. van Albada, J. Dongarra, SP.M.A., loot (eds.) Computational Science - ICCS 2007. Berlin, Heidelberg: Springer, https://doi.org/10.1007/978-3-54072586-2_22

Vaca Torres, A. M., \& Gómez Rodríguez, L. F. (2017). Increasing EFL learners' oral production at a public school through project-based learning. PROFILE, 19(2), 57-71.

http://dx.doi.org/10.15446/profile.v19n2.59889 
Wexler, L., Eglinton, K., \& Gubrium, A. (2014). Using digital stories to understand the lives of Alaska Native young people. Youth and Society, 46(4), 478-504.

Yang, Y. T. C., \& Wu, W. C. I. (2012). Digital storytelling for enhancing student academic achievement, critical thinking, and learning motivation: A year-long experimental study. Computers and Education, 59(2), 339-352.

https://doi.org/10.1016/j.compedu.2011.12.012 